\title{
The Role of the Ocean and Ocean Data in Weather Forecasting
}

\author{
Roberto Buizza* \\ Centre for Climate Change studies and Sustainable Actions, Scuola Superiore Sant'Anna, Pisa, Italy
}

Submission: July 01, 2020; Published: July 28, 2020

Corresponding author: Roberto Buizza, Centre for Climate Change studies and Sustainable Actions, Scuola Superiore Sant'Anna, Piazza Martiri della Liberta, Pisa, Italy

\begin{abstract}
In the past decade we have seen an increased convergence between the numerical models used for weather prediction and for climate studies. Today, both operational weather prediction and climate projections are generated with similar coupled models that include all relevant processes of the atmosphere, land surface, cryosphere, and the dynamical ocean. For weather prediction over the sub-seasonal and seasonal time scale, and for decadal predictions, having an accurate estimate of the ocean initial conditions is paramount. To improve the estimate of the ocean initial conditions, many good quality observations that cover the global oceans would be necessary: unfortunately, to date the ocean remains under-observed. In this paper, two key topics are discussed: firstly, the role of coupling a numerical weather prediction to a dynamical ocean model, and secondly the need for more, better quality observations of the ocean.
\end{abstract}

Kewords: Dynamical ocean model; Ocean observations; Earth-system models; Numerical weather prediction; Data assimilation; Predictability

\section{The Role of the Ocean in Medium-range Weather Fo- recasting}

Numerical weather prediction (NWP) relies on the integrations of an appropriate and relevant formulation of fluiddynamics equations of the 'system' starting from initial states determined by merging most recently available observations with short-range forecasts, issued from most recent forecasts. For example, the European Centre for Medium-Ranger Weather (ECMWF) forecast that started at 12 UTC (Coordinated Universal Time) of 14 May 2017, used as initial conditions the state of the system at 12 UTC, estimated by merging observations collected between in the hours before 12 UTC and a 12-hour forecast that started at 00 UTC.

Up to the end of the 1980s, the ECMWF modelled 'system' included only the atmosphere and the land: in other words, the ECMWF model used to generate the forecasts included only a representation of the atmosphere and land processes (e.g. the water cycle, clouds, radiation, turbulence and surface drag). In the end of the 1980s, results indicated that including a model of the ocean waves [1] would improve the forecast accuracy, since with this addition the model would be able to re-compute at each time-step the surface fluxes (of energy and momentum) between the lower part of the atmosphere and the ocean surface, thus capturing their flow dependency. In terms of forecast length, up to the end of the 1980s operational forecasts were issued up to no more than 10 days. It is only in 1990s that operational centres started developing and making available forecasts with longer forecast lengths, covering few weeks and even few months.

Three key aspects made it possible to issue skilful monthly and seasonal forecasts: (a) the adoption of ensemble techniques, (b) model improvements and (c) initial conditions improvements $[2,3]$. These three aspects are interlinked, and they all contributed not only to the establishment of skilful monthly and seasonal ensemble prediction systems, but also to the improvement of the accuracy of short- and medium-range forecasts. Ensembles are needed to estimate the predictability and filter, in a flowdependent way, unpredictable features, better models are needed to reduce the growth rate of errors, and better initial conditions are required to start the numerical integrations as close as possible to the truth. Furthermore, better models allow more observations to be used in the computation of the initial conditions.

One of the key model upgrades that made it possible to issue skilful monthly and seasonal forecasts and to improve NWP 
forecasts on all forecast ranges, was the coupling of atmosphere, land and ocean-waves models to 3-dimensional models of the ocean [4-6]. As a result, today the ECMWF modelled 'system' includes also the 3-dimenrional ocean: the introduction of a flow-dependent coupling to the 3-dimensional ocean has made it possible to extract predictable signals from the ocean. For example, ECMWF experiments have clearly shown that the skill of the Madden-Julian-Oscillation (MJO), a pattern of organized convection over the tropics that affects the extra-tropical weather, would deteriorate substantially if the 3-dimensional ocean would be removed from the ECMWF model (Frederic Vitart, personal communication, 2018).

Table 1 illustrates the key characteristics of the ECMWF forecast components at the time of writing (June 2020): they include three assimilation systems, which are used to generate the initial conditions for the atmosphere, land and waves (4dVar and EDA) and for the 3D-ocean (ORAS5), the high-resolution forecast model (HRES), and the two ensembles. Note that all the forecasts are generated with a coupled atmosphere, land, ocean-waves and 3D-ocean model: the 3D-ocean model is NEMO, the Nucleus for European Modelling of the Ocean, which includes the LIM2 sea-ice model (the Louvain-la-Neuve sea-ice model). It is worth mentioning that the high-resolution model (HRES) was also coupled to the dynamical ocean in 2018, since the introduction of the coupling had, a substantial impact on the accuracy of tropical cyclone forecasts [7].

\begin{tabular}{|c|c|c|c|c|c|}
\hline $\begin{array}{l}\text { Forecast } \\
\text { component }\end{array}$ & Description & $\#$ & $\begin{array}{l}\text { Horizontal and } \\
\text { vertical resolution }\end{array}$ & FC length & $\begin{array}{l}\text { 3D-Ocean and } \\
\text { sea-ice }\end{array}$ \\
\hline $\begin{array}{l}\text { 4DVar } \\
\text { analysis }\end{array}$ & $\begin{array}{l}\text { Atm/land/waves } \\
\text { High-resolution analysis }\end{array}$ & 1 & 9 km - 137 Vert-lev & - & No \\
\hline $\begin{array}{c}\text { EDA }^{25} \\
\text { analyses }\end{array}$ & $\begin{array}{c}\text { Atm/land/waves } \\
\text { Ensemble of Data Assimilation }\end{array}$ & 25 & $18 \mathrm{~km}-137$ Vert-lev & - & No \\
\hline $\begin{array}{c}\text { ORAS }^{55} \\
\text { analyses }\end{array}$ & $\begin{array}{c}\text { 3D-Ocean } \\
\text { Ensemble of analyses }\end{array}$ & 5 & 25 km - 75 Vert-lev & - & $25 \mathrm{~km}-75$ Vert-lev \\
\hline $\begin{array}{l}\text { HRES } \\
\text { forecast }\end{array}$ & $\begin{array}{l}\text { Atm/land/waves } \\
\text { High-resolution }\end{array}$ & 1 & 9 km - 137 Vert-lev & $10 \mathrm{~d}$ & $25 \mathrm{~km}-75$ Vert-lev \\
\hline \multirow{2}{*}{$\begin{array}{c}\text { ENS }^{51} \\
\text { forecast }\end{array}$} & \multirow{2}{*}{$\begin{array}{c}\text { Atm/land/wave/3D-Ocean } \\
\text { Medium range/monthly ensemble }\end{array}$} & \multirow{2}{*}{51} & 18 km - 91 Vert-lev & $15 \mathrm{~d}$ & \multirow{2}{*}{$25 \mathrm{~km}-75$ Vert-lev } \\
\hline & & & 36 km - 91 Vert-lev & $15-46 \mathrm{~d}$ & \\
\hline \multirow{2}{*}{$\begin{array}{l}\text { SEAS5 }^{51} \\
\text { forecast }\end{array}$} & \multirow{2}{*}{$\begin{array}{l}\text { Atm/land/waves/3D-Ocean } \\
\text { Seasonal ensemble }\end{array}$} & \multirow{2}{*}{51} & \multirow{2}{*}{36 km - 91 Vert-lev } & $7 \mathrm{~m}$ & \multirow{2}{*}{$25 \mathrm{~km}-75$ Vert-lev } \\
\hline & & & & $13 \mathrm{~m}$ & \\
\hline
\end{tabular}

Table 1: Key configuration of the 6 ECMWF Forecast components run operationally at the time of writing (February 2018): description (column 2), number of members (column 3), resolution of the atmosphere/land components (column 4), forecast length (column 5) and coupled ocean/sea-ice model and resolution of the ocean model (column 6) and resolution of the 3D-ocean component. In column 1, EDA25 denotes the 25-member Ensemble of Data Assimilation, ORAS55 denotes the 5-member Ocean Reanalysis System-5, HRES the high-resolution model, ENS the mediumrange/monthly ensemble, SEAS5 the Seasonal System-5. In column 6, NEMO is the ocean model and LIM is the sea-ice model.

\section{The Need for More and Better Ocean Data}

Having good-quality ocean initial conditions is essential to have a positive impact of coupling the atmosphere and ocean models. At ECMWF, the ocean initial conditions are generated using ORAS5 [8], the ocean data assimilation scheme that generates the 5 analyses used to initialize the 3D-ocean component of the ECMWF coupled forecasts (today, the ensembles, and from mid-2018 also the highresolution model version). ORAS5 relies on ocean observations from moored buoys, sondes, expendable bathy-thermographs and ARGO floats. The data assimilation systems used to compute the initial conditions for the atmosphere and land components, and for the 3D-ocean (Table 1) are all based on variational methods, the only difference being that the atmosphere/land assimilation is 4-dimensional (i.e. it includes also a temporal aspect). The major difference between the two assimilation systems is in the number of observations that they use.

For the atmosphere and the land-surface components, for example, every day about $640 \mathrm{M}$ observations covering the atmosphere and the land are received, and of these about $40 \mathrm{M}$ are used to compute the initial conditions. By contrast, only about $0.25 \mathrm{M}$ observations of the ocean are received, and of these about 30,000 are used to compute the ocean initial conditions. There is a clear disparity between these numbers, with the atmosphere having more than a factor of 1,000+ less observations. An example of this discrepancy is given by Figure 1, which shows the number of ocean salinity observations (top) and surface mean-sea-levelpressure observations (bottom), used at ECMWF to generate the initial conditions on a day in October 2017. If we want to exploit 
more the predictable signals coming from the ocean, and improve the quality of NWP, especially in the sub-seasonal and seasonal forecast range, we need to initialize better the ocean, and to achieve this we need more, higher quality ocean data.

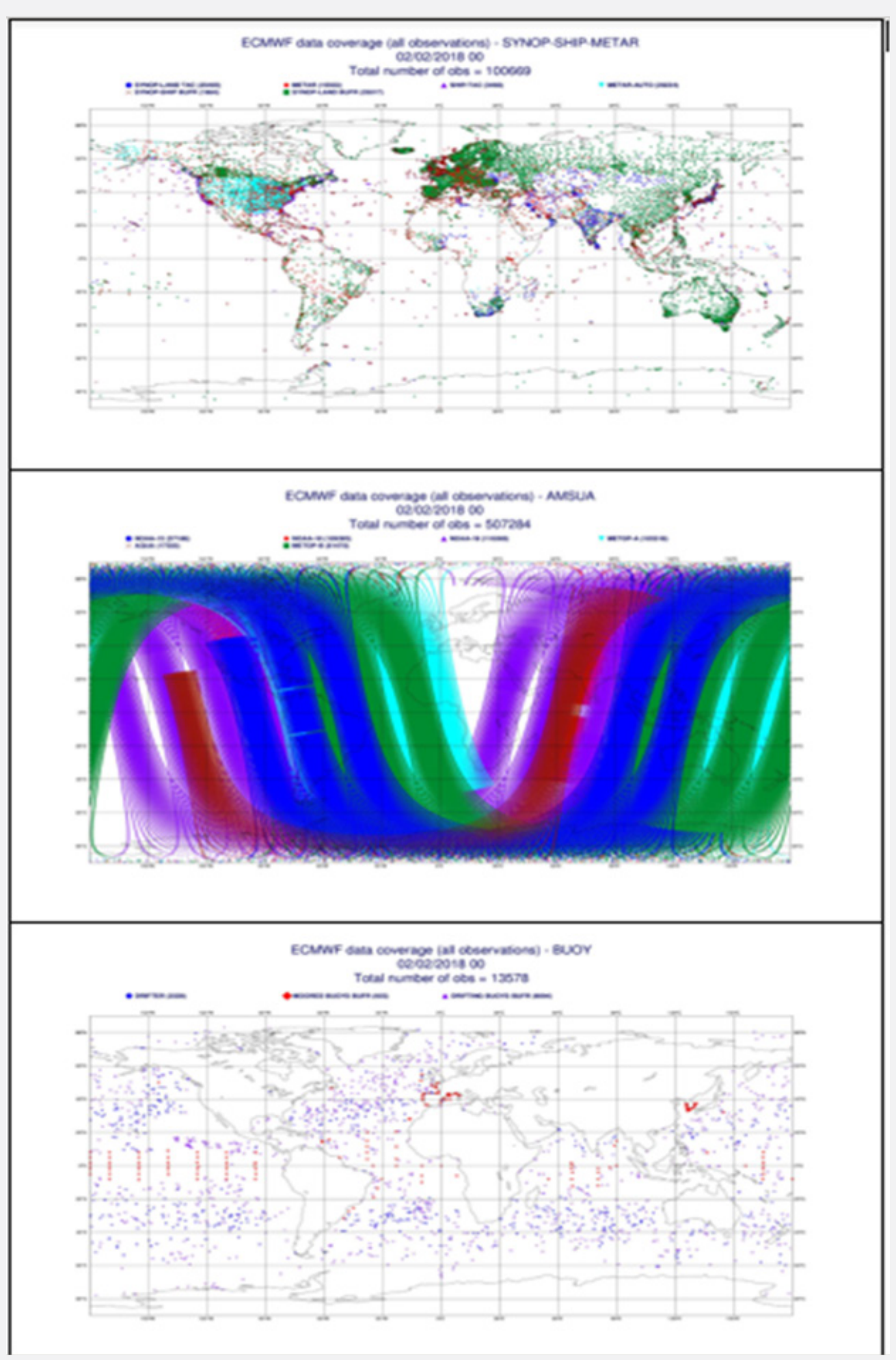

Figure 1: Example of location and number of atmosphere, land and ocean observations on 2 February 2018 (00 UTC) from synop, ships and metar (top, 100,000), AMSUA satellite instruments (middle; 500,000 ) and buoys (bottom; 13,000) (Source: ECMWF). 


\section{How do we Expect NWP to Change in the Future?}

The demand for accurate predictions on all time ranges continue to increase. Furthermore, the request for accurate and skilful (i.e. better than climatological estimates) multi-year and decadal predictions keep increasing. Given the role of the ocean as a potential source of long-range predictable signals, we expect that also the demand for more and better ocean data will increase. More generally, we expect that the forecast skill can be further extended in the future, if we continue to advance in three key areas:

I. Availability of more, and more accurate observations of all the Earth-system components that are relevant for weather prediction: these observations are required to improve the forecast initial conditions.

II. Better models: they are required to improve the simulation of all relevant physical processes; please note that with the term 'model', we mean also models of 'model uncertainties' needed to improve the reliability and accuracy of ensembles;

III. Better data assimilation systems: one area where we expect changes is in the development of more strongly coupled data assimilation systems [9], so that the initial states of, e.g., the 3D-ocean (including the ocean waves) and the lower atmosphere are more consistent.

At ECMWF, for example, the 2016-2025 strategy (accessible from the ECMWF web site) relies on advances along these three areas, and more specifically on the development of better, ensembles of coupled models starting from coupled initial conditions. Coupled assimilation systems are expected to generate also more accurate reanalyses spanning the past decades, thus allowing a better and more coherent understanding of the evolution of the whole Earth-system: an example of is given by CERA-20C, the first ensemble of coupled reanalyses of the $20^{\text {th }}$ century (1901-2010) produced at ECMWF within the ERA-CLIM2 project [10-13]. Clearly, to be able to make progress on the three areas mentioned above we will require more resources:

- $\quad$ Financial, to increase the number of observations and the human and computer resources available to process and utilize them timely, efficiently, and effectively.

- Human, to improve our scientific understanding and to develop better models and assimilation systems capable to assimilate all the available observations.

- $\quad$ Computational, to be able to run more reliable ensembles of more realistic models, which include more processes and better simulations of model approximations; and to run more complex, and strongly coupled, data assimilation systems.

It is hoped that the scientific community will be given access to these resources, so that we can continue to advance and provide users with more accurate, and reliable weather services.

\section{References}

1. Janssen P, J R Bidlot, Abdalla and H Hersbach (2005) Progress in ocean wave forecasting at ECMWF. ECMWF Research 478.

2. Buizza R, and Leutbecher M (2015) The Forecast Skill Horizon. Q J Roy Meteorol Soc 141(693): 3366-3382.

3. Bauer P, Thorpe A, Brunet G (2015) The quiet revolution of numerical weather prediction. Nature 525: 47-55.

4. Molteni F, T Stockdale, M Balmaseda, G Balsamo, R Buizza, et al. (2011) The new ECMWF seasonal forecast system. ECMWF Research Department Technical Memorandum 656.

5. Mogensen K, S Keeley and P Towers (2012) Coupling of the NEMO and IFS models in a single executable. ECMWF Research Department Technical Memorandum 673: 23.

6. Vitart F, Balsamo G, Buizza R, Ferranti L, Keeley S, et al. (2014) Subseasonal predictions. ECMWF Research Department Technical Memorandum 738: 45.

7. Mogensen K S, Magnusson L, and Bidlot J R (2017) Tropical Cyclone Sensitivity to Ocean Coupling. ECMWF Research Department Technical Memorandum 794: 25.

8. Zuo H, Alonso-Balmaseda M, de Boisseson E, Hirahara S, Chrust M, et al. (2017) A generic ensemble generation scheme for data assimilation and ocean analysis. ECMWF Research Department Technical Memorandum 795: 46.

9. Bonavita M, Trémolet Y, Holm E, Lang S T K, Chrust M, et al. (2017) A Strategy for Data Assimilation. ECMWF Research Department Technical Memorandum 800: 44.

10. Buizza R, Brönnimann S, Fuentes M, Haimberger L, Laloyaux P (2018) The ERA-CLIM2 project. Bull Amer Met Soc.

11. Janssen PAEM, O Breivik, K Mogensen, F Vitart, M Balmaseda, et al. (2013) Air-sea interaction and surface waves. ECMWF Research 712.

12. NEMO the Nucleus for European Modelling of the Ocean, a state-ofthe-art modelling framework for oceanographic research, operational oceanography seasonal forecast and climate studies.

13. S2S the WMO Sub-seasonal to Seasonal prediction research project. 
This work is licensed under Creative

Commons Attribution 4.0 Licens

DOI: 10.19080/OFOAJ.2020.12.555831
Your next submission with Juniper Publishers will reach you the below assets

- Quality Editorial service

- Swift Peer Review

- Reprints availability

- E-prints Service

- Manuscript Podcast for convenient understanding

- Global attainment for your research

- Manuscript accessibility in different formats ( Pdf, E-pub, Full Text, Audio)

- Unceasing customer service

Track the below URL for one-step submission https://juniperpublishers.com/online-submission.php 